\title{
O ponto de vista de jovens mulheres de duas gerações sobre a possibilidade de manter $o$ amor na conjugalidade
}

\section{The point of view of young women of two generations about the possibility of maintaining love in conjugality}

\author{
Jussara Abilio Galvão ${ }^{1}$, Heloisa Moulin de Alencar ${ }^{2}$, Ariadne Dettmann Alves ${ }^{3}$
}

Resumo

Em uma perspectiva moral e ética, investigamos a concepção de mulheres sobre a possibilidade de os casais em geral manterem o amor na conjugalidade. Participaram desta pesquisa 15 mulheres entrevistadas por Alencar (1993) e 15 mulheres entrevistadas atualmente, entre 20 e 30 anos, casadas, sem filhos e, na classe média. Utilizamos um instrumento semiestruturado e priorizamos a análise qualitativa dos dados (DELVAL, 2002). Constatamos que a maioria das entrevistadas considerou a possibilidade de o amor permanecer na conjugalidade. Como justificativas, elas mencionaram, os sentimentos, e as entrevistadas, no passado, enfatizaram a experiência. Os problemas conjugais, a intolerância, a incompreensão e a abdicação somaram $18 \%$ dos argumentos indo de encontro à ética do cuidado e ao plano psicológico ético, que deve contemplar o eu e outrem na busca por uma vida boa. Este trabalho contribui para as pesquisas e fornece subsídios teóricos a psicólogos que trabalham com o tema em questão.

Palavras-chave: Casamento. Amor. Virtude. Moral. Ética.

\begin{abstract}
From a moral and ethical perspective, we investigate the conception of women about the possibility of couples in general maintaining love in conjugality. Fifteen women interviewed by Alencar (1993) and 15 women currently interviewed, between 20 and 30 years old, married, without children, and in the middle class, participated in this study. We used a semi-structured instrument and prioritized qualitative data analysis (DELVAL, 2002). We found that most interviewees considered the possibility of love remaining in conjugality. As justification, they mentioned feelings, and interviewees, in the past, emphasized experience. Marital problems, intolerance, incomprehension and abdication accounted for $18 \%$ of the arguments going against the ethics of care and the ethical psychological plan, which should consider the self and others in the pursuit of a good life. This work contributes to the researches and provides theoretical reference to psychologists who work on the issue in question.
\end{abstract}

Keywords: Marriage. Love. Virtue. Moral. Ethic.

1 Psicóloga CRP 16/5289 pela Universidade Federal do Espírito Santo (Ufes). Mestre em Psicologia pelo Programa de PósGraduação em Psicologia da Universidade Federal do Espírito Santo (Ufes). E-mail: jussaraabgalvao@hotmail.com

2 Doutora em Psicologia pela Universidade de São Paulo. Professora do Departamento de Psicologia Social e do Desenvolvimento e do Programa de Pós-graduação em Psicologia da Universidade Federal do Espírito Santo (Ufes). Coordenadora do Laboratório de Psicologia da Moralidade (Lapsim) da Ufes.

3 Doutora em Psicologia pelo Programa de Pós-graduação em Psicologia da Universidade Federal do Espírito Santo (Ufes). Professora da faculdade Doctum-Serra, Espírito Santo. 


\section{Introdução}

Segundo Ferry (2013), do feudalismo ao século XVII, o amor não era considerado fundamental para o casamento, pois os matrimônios eram combinados pelas famílias dos noivos e visavam principalmente à manutenção de bens materiais. Tal fato começou a se modificar com a Revolução Industrial, que permitiu às mulheres certa autonomia financeira e a possibilidade de escolherem um parceiro conforme o amor. Dessa maneira, o autor explicou que o casamento baseado no amor nasceu primeiramente no meio operário europeu e se estendeu à burguesia, em virtude de questões financeiras, e às demais regiões do mundo após a Segunda Guerra Mundial.

Assim sendo, começaram a emergir, no fim do século XX, diferentes formas de se relacionar como casal, por exemplo: Giddens (1993, p. 72) destacou o casamento por companheirismo que se edifica na igualdade e na simpatia recíproca e o 'amor confluente' que supõe a reciprocidade na doação e na aceitação emocional entre os parceiros. Porém, o 'amor confluente' é um amor transitório, ativo e contrário às noções de "para sempre" e "único" do amor romântico, pois, nessa forma de amor, os parceiros tendem a permanecer juntos somente até quando a relação amorosa for satisfatória para ambos. Desse modo, os divórcios podem ser mais um efeito do surgimento do 'amor confluente' do que a sua causa.

Ferry (2013) ainda ressaltou que a banalização do divórcio nos dias atuais pode estar relacionada com a inserção do amor no seio conjugal, pois pautar um casamento apenas no amor- paixão equivale a tentar construí-lo em um terreno frágil e instável. Também Vieira e Stengel (2010), em estudo realizado com três casais, nas idades entre 28 e 40 anos, constataram que, para alguns dos entrevistados, a separação será algo aceitável se o casamento se tornar insatisfatório. Coutinho e Menandro (2010), na pesquisa com 10 mulheres que foram mães nos anos de 1960 e com 10 mulheres que foram mães na década de 1990, verificaram que, na concepção de algumas participantes, atualmente as pessoas se casam pensando no divórcio. Chaves (2010), ao entrevistar 12 sujeitos, nas idades entre 18 e 25 anos, de ambos os sexos, notou que, para a maioria desses jovens, a facilidade de separação contribui para as mudanças nas relações amorosas.

Por sua vez, Bauman (2004, p. 26) considerou que os casamentos tradicionais "até que a morte nos separe" estão sendo preteridos pelo "ficar junto" em período parcial e/ou flexível. Além disso, Costa (2004) assinalou que a instituição familiar vem sendo desestabilizada pela 'moral do espetáculo', que se caracteriza pelo ideal da felicidade das sensações e da vida como entretenimento. $\mathrm{Na}$ 'moral do espetáculo', os caminhos para atingir a felicidade e o sentido da vida são difundidos pela mídia e apreendidos pelas pessoas de modo passivo, sem que haja uma avaliação do que é apresentado. Também os sujeitos (nove pessoas casadas, de ambos os sexos, de idades entre 40 e 57 anos) entrevistados por Costa e Mosmann (2015) esclareceram que a mídia pode interferir nas relações amorosas, colaborando para o egoísmo, a intolerância às diferenças e às frustrações e a mudança do que se espera do enlace amoroso.

Assim sendo, vimos que, para Costa (2004), a sociedade, neste início de século, se caracteriza por uma 'moral do espetáculo', a qual possui como instrumento a mídia, que é capaz de influenciar os relacionamentos amorosos (COSTA; MOSMANN, 2015). Ademais, La Taille (2009) discutiu que vivemos em uma 'cultura do tédio' em que as tradições do passado e as expectativas sobre o futuro perderam a sua influência na atribuição do sentido da vida pelas pessoas. O autor ainda definiu os planos moral e ético, conferindo à ética a busca por uma vida boa e feliz para si próprio e para o outro e à moral o âmbito das obrigações/deveres para com outrem e a sociedade (LA TAILLE, 2010).

Contudo, bem antes de La Taille (2010) definir os planos moral e ético, a moralidade humana foi 
investigada por Piaget (1994). O autor constatou que, por volta dos seis anos de idade, das relações de coação e do respeito unilateral à autoridade adulta emerge a heteronomia moral e, ao redor dos nove anos, das relações de reciprocidade e do respeito mútuo surge a autonomia moral, caracterizada pela construção da capacidade de colocar-se no ponto de vista alheio. Porém, em suas pesquisas, Piaget (1994) entrevistou principalmente sujeitos do sexo masculino e enfatizou o ideal de justiça.

Com base nisso, Gilligan (1982) ampliou os estudos sobre a moralidade, investigando o desenvolvimento do juízo moral de mulheres. A autora averiguou que as mulheres apresentam um desenvolvimento moral voltado para uma 'ética do cuidado’, da compreensão das responsabilidades e das obrigações para consigo mesmo e para com os outros. Uma ética que busca corresponder às necessidades e ao bem-estar de todas as pessoas envolvidas na relação, de modo que ninguém seja excluído. Assim, as mulheres tendem a se definir e a se avaliar em um contexto de relacionamentos no qual desempenham um papel de cuidadora, de companheira, isto é, daquela que tece as relações, visando à manutenção dos laços entre os sujeitos.

Cabe sublinhar que as pesquisas realizadas por Piaget (1994) e os estudos desenvolvidos por Gilligan (1982) podem ter sido influenciados pelos modelos de conduta em voga, até meados do século XX. Nesse contexto, segundo Del Priore (2014), a esfera pública era destinada ao homem e a privada à mulher. Assim sendo, o marido era considerado o chefe de família, detentor da autoridade sobre a esposa e os filhos, e a mulher a responsável pela manutenção do casamento, pelo cuidado do lar, do marido e dos filhos. Desse modo, destacamos que esses fatores sociais, explicitados por Del Priore (2014), podem ter conduzido Piaget (1994) a priorizar estudos com sujeitos do sexo masculino, e, provavelmente, estavam implicados na constituição subjetiva das mulheres entrevistadas por Gilligan (1982).
Por sua vez, La Taille (2001) ressaltou que o que esclarece a passagem da heteronomia moral para a autonomia moral é mais a tendência de considerar outrem em sua singularidade do que a conscientização desse outro como sujeito de direito. De tal modo, na trajetória da construção do ideal de justiça, todas as virtudes que consideram outrem em sua particularidade, por exemplo, a tolerância, o amor e o humor, desempenham uma função e, por esse motivo, são merecedoras de investigação por parte do psicólogo. Ainda, Comte-Sponville (1999) explanou que as virtudes são os valores morais do homem vividos na ação, possíveis de ser adquiridas por meio da educação e de exemplos. Dessa maneira, neste estudo optamos por investigar a virtude do amor e, assim, indagamos: O que seria o amor?

Comte-Sponville (2011) apresentou os três nomes gregos do amor, a saber: éros, philía e ágape. Desse modo, éros é o amor-paixão que sentimos quando estamos apaixonados e é o amor, conforme Platão em $O$ banquete, definido pela incompletude, pela carência e pela falta. Porém, com a convivência diária, essa paixão amorosa pode transformar-se em amor philía, no qual amamos alegremente a pessoa que está presente em nosso dia a dia. Por fim, ágape é o amor divino e universal. É o amor da caridade e da renúncia em que buscamos amar o outro para o bem dele em detrimento do nosso bem.

Além disso, Jablonski (1991) proferiu que, no início de uma relação amorosa, encontramos o amorpaixão e, nos casos em que a união permanece, essa forma de amor se modifica em amor companheiro, no qual predominam o companheirismo, a amizade e o que se concretiza por meio do convívio em comum. Segundo Ferry (2013), o amor-paixão dura pouco e, se o casal desejar sobreviver ao esvanecimento desse amor, deve modificá-lo em algo mais sólido, por exemplo, em uma amizade amorosa. Também, em um estudo realizado com 22 mulheres, entre 30 e 40 anos de idade, Aboim (2009) constatou que, para a maioria das entrevistadas, o início da vida 
conjugal foi caracterizado pela paixão amorosa que, com a convivência diária e com o nascimento dos filhos, se transformou em um amor-amizade.

De tal modo, no entender de Comte-Sponville (2011), Ferry (2013), Jablonski (1991) e das entrevistadas por Aboim (2009), o amor pode transformar-se com o convívio diário. Ademais, convém indagar: $\mathrm{O}$ que dizem as pesquisas sobre o conceito de amor? Estrella (2011) pesquisou a concepção de amor com 32 adolescentes, de ambos os sexos, entre 15 e 17 anos de idade. Os entrevistados mencionaram como definição de amor o respeito, o sentimento, o carinho, a amizade e Deus. No estudo de Alves (2016) com 40 adolescentes de 12 e 15 anos, de ambos os sexos, os participantes citaram o sentimento e a amizade para conceituar o amor e sublinharam a experiência vivenciada tanto por outros quanto por eles próprios como justificativas para os conceitos de amor, a possibilidade de amar ou não outro adolescente do sexo oposto, um amigo, um desconhecido e um inimigo. Em Alves et al. (2015a) os seis adolescentes entrevistados, de 12, 15 e 18 anos, de ambos os sexos, expuseram o sentimento ao próximo, a amizade e o amor a Deus como exemplos de amor e justificaram as suas respostas com base na experiência vivenciada.

Alves et al. (2015b) ainda pesquisaram o conceito de amor com 17 mulheres casadas, entre 20 e 30 anos. Assim, para definir o amor, as entrevistadas citaram a amizade, Deus, o companheirismo, o respeito, o carinho, o sentimento e a abdicação. Ademais, nas pesquisas realizadas com 40 crianças, de seis e nove anos, de ambos os sexos, os infantes mencionaram o sentimento (ALVES; ALENCAR; ORTEGA, 2014) e o amor a Deus, ao conceituarem o amor (ALVES; ALENCAR; ORTEGA, 2012, 2014), e justificaram as suas respostas aludindo à consequência positiva recíproca (ALVES; ALENCAR; ORTEGA, 2012, 2014).

Por sua vez, Costa e Fernandes (2012) investigaram as representações sociais do amor com 301 adolescentes solteiros, de ambos os sexos, entre
12 e 18 anos. As pesquisadoras verificaram que as categorias mais evocadas pelos participantes para o vocábulo amor foram companheirismo (64,8\% dos adolescentes), carinho (54,8\% dos participantes) e sentimento (42,2\% dos adolescentes). Porém, a categoria compreensão, que inseriu a tolerância, foi evocada por apenas $10,3 \%$ dos adolescentes. Além do mais, os jovens no estudo de Chaves (2010) explicaram que o amor é um sentimento forte e profundo, capaz de aproximar as pessoas e de leválas ao anseio por estar juntas. Na pesquisa de Fonseca e Duarte (2014), realizada com cinco casais, entre 26 e 37 anos, os entrevistados mencionaram que o amor é a compreensão mútua e a preocupação com a felicidade do outro e que no namoro esperavam encontrar no parceiro amoroso o companheirismo.

Também no estudo Stengel e Tozo (2010), os sete adolescentes, de ambos os sexos, entre 15 e 19 anos, esclareceram que estimam em um parceiro amoroso o amor, o companheirismo e a amizade. Marimón e Vilarrasa (2014), em uma investigação realizada com 160 universitários solteiros, de ambos os sexos, entre 18 e 24 anos, constataram que os participantes esperam da pessoa amada a reciprocidade no amor e nos comportamentos e buscam encontrar no parceiro e/ou no casal o carinho, o respeito, o sacrifício, a felicidade, a amizade e a entrega total. No trabalho de Zordan, Falcke e Wagner (2009), com 197 pessoas solteiras, 120 mulheres e 77 homens, entre 20 e 31 anos, os participantes explicaram que esperam do casamento principalmente o amor e o companheirismo.

Além disso, Smeha e Oliveira (2013), na pesquisa com oito sujeitos, de ambos os sexos, entre 18 e 23 anos, verificaram que os participantes procuram, em um enlace amoroso, a confiança mútua, o diálogo sincero, o respeito e alguém responsável. Ainda, Silva, Menezes e Lopes (2010), ao entrevistarem cinco casais de noivos, entre $21 \mathrm{e}$ 32 anos, notaram que os participantes valorizavam, em seus relacionamentos amorosos, o carinho e o amor no casal, a participação recíproca nas ideias e o diálogo. 
Sobre os motivos que conduzem as pessoas ao matrimônio, Marimón e Vilarrasa (2014) explicaram que o amor ainda é compreendido como uma das melhores motivações para a união conjugal. Jablonski (1991), ao entrevistar 400 sujeitos de ambos os sexos, divididos entre solteiros, casados e divorciados, verificou que, para os entrevistados, o amor é o principal motivo para o casamento. Carvalho e Paiva (2009) pesquisaram a percepção de seis mulheres de três diferentes gerações acerca do casamento. As autoras averiguaram que, para as entrevistadas mais jovens, o matrimônio deve acontecer principalmente por amor. Ainda as mulheres mais jovens, em Coutinho e Menandro (2010), destacaram o amor e o fato de a união ser obra divina como motivos para o casamento. Em Zordan, Falcke e Wagner (2009) os jovens mencionaram como motivação para a união o amor, a certeza do sentimento pelo outro, a fé de quem considera o casamento sagrado e o fato de o matrimônio ser valorizado em várias religiões.

Cabe ressaltar que Llosa (2013) ponderou que a religiosidade é de suma relevância para a maioria dos sujeitos, pois somente a segurança difundida por meio da fé pode libertar o homem da inquietação, do medo, da finitude humana. Além do mais, para Cortella e La Taille (2005, p. 23), estamos assistindo ao ressurgimento "das estruturas religiosas", já que, em nenhum outro momento histórico, tantas formas de religiosidade puderam ser vistas, conforme observamos atualmente.

De tal modo, a influência da religiosidade com a responsabilidade, o amor entre os cônjuges, a crença no matrimônio como uma parceria entre o casal e o diálogo foram verificados como aspectos relevantes para a manutenção de um casamento de longa duração na revisão de literatura realizada por Alves-Silva, Scorsolini-Comin e Santos (2016). Também Matos, Féres-Carneiro e Jablonski (2005), em um estudo com 10 sujeitos de ambos os sexos, entre 13 e 17 anos, conferiram que os adolescentes consideram que o amor e o respeito concorrem para a manutenção de uma relação amorosa e buscam a pessoa certa para um enlace futuro duradouro. No trabalho de Jablonski, (1991) os entrevistados ressaltaram que o amor, o respeito mútuo, o companheirismo e a sorte podem contribuir para a permanência da união amorosa.

Em Vieira e Stengel (2010), a metade dos entrevistados destacou a necessidade de abrir mão da individualidade em favor da manutenção do casamento. Os participantes, na pesquisa de Costa e Mosmann (2015), explicaram que o respeito coopera com a conservação da união amorosa, e o companheirismo e a amizade são construídos no casamento e a maturidade torna a conjugalidade mais feliz e estável, pois o casal aprende a lidar construtivamente com os conflitos. Ademais, Del Priore $(2014$, p. 101) expôs que atualmente se tende a crer que o sucesso de uma relação amorosa provém da "valorização de um compromisso em longo prazo", isto é, de um investimento diário no relacionamento, acompanhado da amizade e do respeito mútuo. Por fim, Marimón e Vilarrasa (2014) esclareceram que, para edificar uma vida em comum, é importante que o casal caminhe pela mesma estrada, pois os cônjuges somente conseguirão viver de forma amorosa se estiverem dispostos a construir uma história conjunta na qual os seus sentimentos se combinem com outros aspectos da vida.

Assim sendo, verificamos que Alves-Silva, Scorsolini-Comin e Santos (2016), Matos, FéresCarneiro e Jablonski (2005), Jablonski (2005), Vieira e Stengel (2010), Costa e Mosmann (2015), Del Priore (2014) e Marimón e Vilarrasa (2014) mencionaram aspectos que podem contribuir para a manutenção de uma relação amorosa. Constatamos que o amor como virtude moral pode emergir, entre as pessoas, por meio da educação e de exemplos (COMTE-SPONVILLE, 1999), o desenvolvimento do juízo moral autônomo requer relações de reciprocidade e de respeito mútuo (PIAGET, 1994), a ‘ética do cuidado' (GILLIGAN, 
1982) e a construção de um plano de vida ético (LA TAILLE, 2010) devem contemplar as necessidades e as singularidades de todos os sujeitos envolvidos na situação. Por outro lado, Ferry (2013), Bauman (2004), Giddens (1993) e Costa (2004) sinalizaram certa fragilidade nos casamentos.

Pautados nessa problemática, este estudo tem por objetivo investigar, em uma perspectiva moral e ética, se há ou não diferenças entre as respostas de mulheres que foram entrevistadas em 1993 por Alencar e as de mulheres que entrevistamos atualmente sobre a concepção e as justificativas para a possibilidade ou não de os casais, de modo geral, manterem o amor na conjugalidade.

Destacamos que não encontramos na literatura um consenso sobre a definição de conjugalidade, muitas vezes não diferenciada da concepção de casamento (OLIVEIRA, 2012; OLTRAMARI, 2009; ROLIM; WENDLING, 2013). Ademais, Rolim e Wendling (2013, p. 173) expuseram que, por um longo período, a conjugalidade se atrelava às expectativas familiares e tradicionais. Porém, segundo os autores retromencionados, atualmente a união conjugal se insere em um "pluralismo de modelos". Nesse contexto, Amorim e Stengel (2014) utilizaram o vocábulo 'customizadas' para definirem as relações conjugais em que os parceiros amorosos combinam valores tradicionais e pós-modernos, constituindo um modo singular de relação conjugal.

Dessa maneira, neste estudo, consideramos por conjugalidade a união entre um homem e uma mulher que dividem o mesmo lar, independente de serem casados no civil e/ou no religioso. Esclarecemos que a relação da conjugalidade com a moralidade refere-se ao fato de que, na união conjugal, os cônjuges podem ou não considerar o bem estar e a felicidade mútua, bem como buscar ou não construir uma relação caracterizada pelo compromisso e pelo dever para com outrem.

Por fim, frisamos que com esta pesquisa, visamos contribuir para os estudos acerca do amor, das relações amorosas, da moral e da ética e levantar subsídios teóricos que auxiliem a prática de psicólogos que trabalham com o tema em questão. Assim sendo, apresentaremos a metodologia utilizada nesta pesquisa.

\section{Método}

\section{Participantes}

Participaram desta pesquisa 15 mulheres que foram entrevistadas por Alencar (1993) e 15 mulheres que entrevistamos na atualidade, sem filhos, que conviviam em conjugalidade com os seus parceiros, entre 20 e 30 anos, da classe média.

Escolhemos entrevistar mulheres sem filhos com vista a neutralizar as possíveis interferências dessa característica nas respostas das participantes. Optamos pela classe média porque, por volta dos anos de 1990, conforme Jablonski (1991), esse segmento social tendia a difundir e/ou impor valores, opiniões e costumes em um amplo número de situações, devido ao significativo controle que exercia sobre os veículos de comunicação e as artes. No início do século XXI, segundo Aboim (2009), as camadas médias urbanas brasileiras são as principais responsáveis pelo distanciamento das práticas e dos valores tradicionais, já que é possível que, nesses grupos sociais, o individualismo e o ideal de igualdade tenham mais expressão, o que pode contribuir para a emergência de diferentes formas de relações amorosas e familiares. Ademais, Senna (2015) explicou que os sujeitos pertencentes à classe média colaboram na construção de novas concepções, favorecendo importantes mudanças sociais igualmente às que temos vivenciado desde a Idade Média.

\section{Instrumento e Procedimentos}

As 30 participantes foram selecionadas por meio de indicação. As entrevistas ocorreram individualmente, em dia, local e hora combinados 
pelas mulheres, foram gravadas em áudio, transcritas na íntegra, cujos protocolos se encontram guardados em arquivos pessoais das pesquisadoras. Utilizamos um instrumento semiestruturado contendo as seguintes perguntas: 1) 'Hoje, em relação aos casais em geral, você acha possível ou não manter o amor na convivência diária?'; 2) 'Por quê?'. Em relação às mulheres entrevistadas atualmente, elas assinaram um termo de consentimento livre e esclarecido no qual explicamos os objetivos desta pesquisa, garantimos $\mathrm{o}$ anonimato $\mathrm{e}$ expusemos que poderiam desistir de participar do trabalho sem sofrerem nenhum prejuízo e que os resultados seriam submetidos à publicação em um periódico científico. Sublinhamos que às mulheres entrevistadas em 1993 não foi entregue nenhum termo de consentimento livre e esclarecido, pois, à época, não havia essa exigência. De tal modo, foi considerado o consentimento verbal dessas participantes. Esclarecemos que este estudo segue as diretrizes da Resolução do Conselho Nacional de Saúde n. ${ }^{\circ}$ 466/2012 e que foi aprovado pelo do Comitê de Ética em Pesquisa com o Parecer n. ${ }^{\circ}$ 419.793 .

\section{Análise dos Dados}

Conforme propõem Delval (2002), priorizamos a análise qualitativa dos dados. Dessa maneira, realizamos uma leitura flutuante dos 30 protocolos de entrevistas no intuito de identificarmos tendências gerais nas respostas das entrevistadas. Feito isso, elaboramos as categorias detalhadas (microcategorias) para as respostas e as justificativas apresentadas pelas mulheres. Em seguida, organizamos as categorias detalhadas em categorias resumidas (macrocategorias) com base no critério de semelhança entre os esclarecimentos apresentados pelas participantes. Por fim, visando à melhor clareza na exposição e na discussão dos resultados, empregamos números e percentuais, e redigimos os nomes das categorias no texto em itálico e entre aspas simples.

\section{Apresentação e Discussão dos Resultados}

Ao indagamos as mulheres se, em relação aos casais em geral, consideravam ou não possível manter o amor na convivência diária, das 15 mulheres entrevistadas no passado, 11 (73,3\%) responderam que é 'é possivel', três disseram que 'depende' (20\%) e uma aludiu que 'não sabe se é possivel' $(6,7 \%)$. Por sua vez, das entrevistadas atualmente, 14 mencionaram que 'é possivel' (93,3\%) e uma proferiu que 'não é possível' (6,7\%).

Destacamos que 19 participantes mencionaram mais de uma justificativa para a possibilidade ou não de os casais em geral manterem o amor no cotidiano. Desse modo, embora o número de entrevistadas tenha sido 30, obtivemos 67 argumentos que organizamos nas categorias resumidas (macrocategorias) expostas na Tabela 1. Esclarecemos que o cálculo da porcentagem foi realizado com base na quantidade de respostas proferidas pelas mulheres. Apenas sublinharemos as diferenças relevantes entre as justificativas das duas gerações de entrevistadas e destacaremos a correspondência entre a resposta e os seus argumentos nas categorias que apresentaram respostas diferentes para a possibilidade ou não de os casais de modo geral manterem o amor na conjugalidade. Empregamos nomes fictícios iniciados com a letra "P" para nos referirmos às participantes entrevistadas no passado e com a letra "A" para as entrevistadas atualmente. 
Tabela 1 - Justificativas para a possibilidade ou não de os casais de modo geral manterem o amor no convívio diário.

\begin{tabular}{lllllll}
\hline Categorias & Passado & \multicolumn{3}{c}{ Atualidade } & \multicolumn{3}{c}{ Total } \\
\hline Sentimentos & $\mathrm{N}$ & $\%$ & $\mathrm{~N}$ & $\%$ & $\mathrm{~N}$ & $\%$ \\
Experiência & 7 & $24,2 \%$ & 11 & $28,9 \%$ & 18 & $26,8 \%$ \\
Reciprocidade & 8 & $27,6 \%$ & 5 & $13,2 \%$ & 13 & $19,4 \%$ \\
Abdicação & 2 & $6,9 \%$ & 4 & $10,5 \%$ & 6 & $8,9 \%$ \\
Problemas conjugais & 2 & $6,9 \%$ & 2 & $5,3 \%$ & 4 & $6 \%$ \\
Incompreensão & 2 & $6,9 \%$ & 2 & $5,3 \%$ & 4 & $6 \%$ \\
Intolerância & 1 & $3,4 \%$ & 1 & $2,6 \%$ & 2 & $3 \%$ \\
Sorte & 0 & $0 \%$ & 2 & $5,3 \%$ & 2 & $3 \%$ \\
Religiosidade & 2 & $6,9 \%$ & 0 & $0 \%$ & 2 & $3 \%$ \\
Questão pessoal & 0 & $0 \%$ & 2 & $5,3 \%$ & 2 & $3 \%$ \\
Companheirismo & 1 & $3,4 \%$ & 1 & $2,6 \%$ & 2 & $3 \%$ \\
Outros & 1 & $3,4 \%$ & 1 & $2,6 \%$ & 2 & $3 \%$ \\
\hline Total & 3 & $10,4 \%$ & 7 & $18,4 \%$ & 10 & $14,9 \%$ \\
\hline
\end{tabular}

Fonte: Dados da pesquisa (2017).

A categoria 'sentimentos' contemplou o maior número de argumentos para a resposta 'é possivel' que os casais de modo geral mantenham o amor na conjugalidade, pois, no entender das participantes, o amor é a base do casamento, amadurece, não se perde no cotidiano e está presente em todas as ações, inclusive nas brigas. Ademais, a paixão e a atração física se transformam em amor ou em um sentimento diferente. Também o amor pode permanecer no casamento devido à falta que um sente do outro, à dedicação ao sentimento e ao sentimento em si mesmo. Vejamos dois relatos que exemplificam essa categoria:

Porque eu acho que na realidade a paixão não se mantém, ela se transforma. No início de uma relação você pode estar até apaixonado, mas depois de um determinado tempo, vem o amor. [...] E porque como se fosse a praia, não é? O amar é uma coisa que te leva, que te carrega [...] Depois de um determinado tempo é como um rio que é calmo, sem onda que você sabe exatamente onde é a margem onde não é, onde é fundo onde é raso. [...] O amor se transforma não é? (Pilar).
[...] porque o amor está em tudo aquilo que você faz, não é? Então, só porque você briga não quer dizer que você não está demostrando amor, não é? Só porque você [...] Fala alguma coisa que o seu parceiro não venha a gostar. Não quer dizer que você não está. Que você não está demostrando o amor. (Alessandra).

Da mesma forma, o casamento pautado no amor foi destacado por Ferry (2013). Nos trabalhos de Carvalho e Paiva (2009), Coutinho e Menandro (2010), Jablonski (1991), Marimón e Vilarrasa (2014) e de Zordan, Falcke e Wagner (2009), o amor emergiu como uma relevante motivação para o matrimônio. Ainda em Jablonski (1991) e em Matos, Féres-Carneiro e Jablonski (2005), os participantes mencionaram que o amor é um ingrediente que contribui para a manutenção do vínculo amoroso. Na pesquisa de Zordan, Falcke e Wagner (2009), os jovens expuseram o amor como expectativa para o enlace amoroso e a certeza do sentimento pelo parceiro motivando a união. Lembramos também que o sentimento foi relacionado ao conceito de amor nas pesquisas de Alves (2016), Alves, et al. 
(2015a, 2015b), Alves, Alencar e Ortega (2014), Chaves (2010), Costa e Fernandes (2012) e de Estrella (2011).

Ademais, o fato de o amor amadurecer e a paixão e a atração física se transformarem em um sentimento diferente ou em amor, no convívio diário, conforme proferido pelas mulheres, condiz com Comte-Sponville (2011), ao explicar que o amor éros, caracterizado pela falta, se modifica em amor 'philía'. Aproxima-se ainda de Jablonski (1991), ao esclarecer que o amor-paixão evolui para o amor companheiro, e de Aboim (2009) e de Ferry (2013), que ressaltaram que a paixão amorosa pode transformar-se em um amor-amizade.

Cabe ressaltar que não foi possível constatarmos nessa categoria a relação do amor com as virtudes morais, já que as entrevistadas enfatizaram os 'sentimentos', e não a singularidade do outro (LA TAILLE, 2001). Também não verificamos a inserção do amor, mediante os discursos das mulheres, na construção do plano ético, o qual consiste na busca por uma vida boa e feliz para si próprio e para outrem (LA TAILLE, 2010). Dessa maneira, sugerimos que se investiguem, em outros estudos, a relação entre o amor, as virtudes morais e o plano ético na conjugalidade.

Por sua vez, a categoria 'experiência' reuniu oito argumentos de mulheres entrevistadas no passado, dos quais sete se referiram à resposta 'é possivel' e um à menção 'não sabe se é possivvel', além de cinco justificativas de mulheres entrevistadas atualmente, três para a declaração 'é possivel' e duas para 'não é possivel'. Dessa maneira, as participantes que alegaram que 'é possivel' manter o amor na conjugalidade justificaram os seus pontos de vista mencionando a maturidade, a experiência pessoal, a observação da experiência vivenciada por familiares e por casais com mais de 50 anos de casados que, apesar das dificuldades, o amor perdura. Sobre a resposta 'não sabe se é possivel', esta obteve por argumento o fato de que os casamentos duradouros estão cada vez mais raros. Já para o 'não é possível' foi proferido que o grande índice de divórcio pode influenciar as demais pessoas. Como exemplo, destacamos os seguintes depoimentos:

[...] Eu fui a uma boda de ouro, cinquenta anos de casada, não é? E eu me pergunto. Não sei, não é? Quer dizer, assim? É uma coisa muito difícil. [...] eu falei: 'Eu vou porque isso é raríssimo, não é?' É uma coisa, assim, que hoje em dia está cada vez mais raro. [...] (Penha).

Hoje em dia, o que mais você ouve falar são as pessoas, 'ah, se eu casar e não der certo, eu vou separar'. Porque, às vezes, o casal já vem de uma família que, eu, por exemplo, meus pais são separados. Então, a minha família já vem de uma história dessas. Meus tios, tudo! A maioria é separada. [...] (Aléxia).

Assim sendo, vimos que as mulheres entrevistadas no passado apresentaram maior quantidade de respostas nessa categoria o que pode estar relacionado com o fato de que essas participantes possuíam um referencial mais sólido nas tradições do passado e nas projeções futuras (LA TAILLE, 2009), intervindo na percepção da própria vivência e na observação da experiência dos outros. A experiência vivenciada também foi mencionada como justificativa para a definição do amor (ALVES, 2016; ALVES; ALENCAR; ORTEGA, 2012, 2014; ALVES et al., 2015a), para a possibilidade de amar ou não outro adolescente do sexo oposto, um amigo, um desconhecido e um inimigo (ALVES, 2016). No estudo de Costa e Mosmann (2015), os entrevistados ressaltaram que a maturidade torna a convivência conjugal mais estável e feliz.

Esses resultados ainda vão ao encontro de Bauman (2004), que enfatizou que os casamentos duradouros estão sendo substituídos por relações amorosas mais flexíveis e efêmeras, e de Chaves (2010), que averiguou que, no entender dos entrevistados, o aumento e a facilidade de separação contribuem para as mudanças nas relações amorosas. Além 
disso, remetem-nos a Giddens (1993), ao explicar que o acréscimo de divórcios pode ser um efeito do amor confluente, e a Ferry (2013), ao esclarecer que a banalização do divórcio pode estar relacionada à emergência do casamento por amor.

Em 'reciprocidade', agrupamos um argumento de uma participante do passado, que alegou que 'depende' ser possível ou não manter o amor na conjugalidade, uma justificativa de outra entrevistada no passado, que proferiu que 'épossivel' e quatro esclarecimentos proferidos por mulheres entrevistadas atualmente, que mencionaram que 'é possivel'. De tal modo, as participantes que disseram que 'é possivel' evocaram a 'reciprocidade' que abrange a sinceridade, fortalece o casal, o bemquerer e o amor entre os cônjuges e permite a tolerância, o respeito e o altruísmo entre o casal. Por seu turno, a entrevistada que declarou que 'depende' ressaltou a eterna troca de informações, de carinhos e de responsabilidades. Observemos o depoimento de Andreia:

Você pode querer bem ao outro, por muito tempo. Desde que o outro também te queira bem, claro? Desde que haja a contribuição. Porque quando não é essa coisa unilateral? Quando é relacionamento, não é? Homem- mulher ou mulher-mulher, homem-homem tem que o do outro, Sabe? Tem que ter a contrapartida.

Com base nessas respostas, vale lembrar que as relações de reciprocidade e de respeito mútuo são imprescindíveis para o desenvolvimento da autonomia moral (PIAGET, 1994). Em trabalhos realizados com crianças, a consequência positiva recíproca foi mencionada como justificativa para os exemplos de amor (ALVES; ALENCAR; ORTEGA, 2012, 2014). Ademais, a participação nas ideias (SILVA; MENEZES; LOPES, 2010), a igualdade e a simpatia recíprocas, a reciprocidade na doação e na aceitação emocional (GIDDNES, 1993), no amor e nos comportamentos (MARIMÓN; VILARRASA,
2014) foram sublinhados como ingredientes relevantes para as relações amorosas.

Além disso, em proximidade com os nossos dados, na pesquisa de Smeha e Oliveira (2013), os jovens explicaram que buscam em um enlace amoroso a confiança mútua, o diálogo sincero e a responsabilidade. Em Fonseca e Duarte (2014), a compreensão mútua foi relacionada ao amor. Por sua vez, o respeito mútuo foi destacado por Del Priore (2014) e, no estudo de Jablonski (1991), como considerável para a manutenção da relação amorosa. Ademais, é importante que em um casal existam o carinho (MARIMÓN; VILARRASA, 2014; SILVA; MENEZES; LOPES, 2010), o respeito (MARIMÓN; VILARRASA, 2014), o amor (ALVES-SILVA; SCORSOLINI-COMIN; SANTOS, 2016; SILVA; MENEZES; LOPES, 2010) e a responsabilidade (ALVES-SILVA; SCORSOLINI-COMIN; SANTOS, 2016).

Isso posto, a 'abdicação' envolveu um esclarecimento de uma mulher entrevistada no passado, que alegou que 'depende' ser possível ou não manter o amor no cotidiano, um argumento de outra participante do passado, que mencionou que 'é possivel', e duas justificativas de mulheres entrevistadas atualmente, que aludiram que 'é possivel'. Assim sendo, essa categoria reuniu os seguintes esclarecimentos: 'depende', porque o sujeito tem que se doar, e 'é possível', desde que a pessoa lute para manter o amor no convívio diário, busque a felicidade do outro, e não a própria, e tenha a disposição de abrir mão do ponto de vista e da história de vida. Como exemplo, destacamos o esclarecimento de Amanda: "[...] Porque a gente tem que buscar não a nossa felicidade, mas a felicidade do outro, não é? Então, assim? Se eu estou buscando a felicidade do outro [...] Vou manter! Para manter esse convívio bem, senão?".

Esse argumento vai ao encontro de ComteSponville (2011), ao explicar que, no amor ágape, caracterizado pela renúncia, amamos o outro para o bem dele, e não para o nosso bem. Também, em 
Alves et al. (2015b), a abdicação foi mencionada como conceito de amor e, em Fonseca e Duarte (2014), os casais proferiram que o amor é preocuparse com a felicidade do outro. Na pesquisa de Vieira e Stengel (2010), a metade dos participantes pontuou a necessidade de abrir mão da individualidade em benefício da relação. Marimón e Vilarrasa (2014) ainda verificaram que os entrevistados esperam do parceiro e da relação amorosa o sacrifício e a entrega total.

Por seu lado, os 'problemas conjugais' referiram-se a duas justificativas de mulheres entrevistadas atualmente, que proferiram que 'não é possivel' manter o amor no convívio diário, e a dois argumentos de participantes do passado, que disseram que 'depende'. Nesse caso, 'não é possivel' conservar o amor na conjugalidade porque as pessoas não querem ou não sabem resolver os problemas conjugais, pois preferem o divórcio e um novo relacionamento. Aliás, 'depende' de o amor permanecer ou não no casal, já que os sujeitos estão brigando pelo poder e buscando controlar a vida do parceiro. O depoimento de Aléxia ilustra essa categoria: "[...] as pessoas, na maioria das vezes, não querem aprender a resolver os problemas, a solucionar. É mais fácil brigar, separar e depois arranjar outro. [...]". Ressaltamos que, em Vieira e Stegel (2010), os entrevistados expuseram a possibilidade da separação se a união se tornar insatisfatória e, em Coutinho e Menandro (2010), as mulheres explicaram que as pessoas se casam pensando no divórcio.

Também a categoria 'incompreensão' uniu um esclarecimento de uma entrevistada no passado, que alegou que 'depende' ser ou não possível o amor permanecer na conjugalidade, pois as pessoas não aceitam muito o outro, e um argumento de uma participante da atualidade, que mencionou que 'não é possível' porque os sujeitos não se entendem devido às diferenças. De tal forma, ressaltamos que esses esclarecimentos se aproximam do estudo de Costa e Fernandes (2012), em que somente 10,3\% dos adolescentes evocaram a compreensão para o vocábulo amor.
Sobre a 'intolerância', nela aliamos argumentos mencionados exclusivamente por mulheres entrevistadas nos dias atuais: uma justificativa foi mencionada por uma mulher que alegou que 'não é possivel' manter o amor no cotidiano, já que as pessoas não são tolerantes e, um esclarecimento foi explanado por uma participante que disse que 'é possivel', embora nem todos os indivíduos considerem a paciência. Assim, proferiu Aléxia: "[...] as pessoas, elas não estão tendo tolerância. [...]". Ponderamos que a 'intolerância' é o oposto da virtude da tolerância que, segundo ComteSponville (1999), é possível de ser desenvolvida por meio de exemplos e da educação.

Além do mais, sublinhamos que as categorias 'abdicação', 'problemas conjugais', 'incompreensão' e 'intolerância', que juntamente somaram $18 \%(n=12)$ das justificativas apresentadas pelas participantes, são contrárias à ética do cuidado, da compreensão, da responsabilidade, que visa satisfazer as necessidades de todos os envolvidos em uma situação (GILLIGAN, 1982). Ainda divergem da edificação do plano ético em que si próprio e o outro devem ser considerados na busca pela vida boa e feliz (LA TAILLE, 2010).

Isso posto, em 'sorte' agrupamos dois esclarecimentos de mulheres entrevistadas no passado, dos quais um se referiu ao 'depende' e o outro ao 'é possível' conservar o amor na conjugalidade. Assim sendo, os dois argumentos corresponderam ao fato de que é uma questão de sorte encontrar a pessoa certa. Observemos as palavras de Paulina: “[...] Eu acho que se você dá sorte, não é? De conhecer a pessoa que, certa para você, não é? [...]". Esse relato vai ao encontro de Matos, FéresCarneiro e Jablonski (2005), que verificaram que os adolescentes entrevistados por eles podem ser vistos como românticos, pois buscam a pessoa certa para um enlace futuro duradouro. Também em Jablonski (1991), a sorte foi aludida como um elemento que contribui para a manutenção do casamento. 
Destacamos que a alusão à 'sorte' nos remeteu à noção do acaso, contribuindo para que as pessoas encontrem o parceiro ideal. Já a 'religiosidade' foi expressa exclusivamente por mulheres entrevistadas atualmente, pois, segundo elas, 'é possível' manter o amor na conjugalidade porque Deus é a base do casamento. Vejamos os seguintes relatos: "[...] você buscar a Deus. Porque eu acho que você ter religião, você ter um Deus, porque você? É a base. [...]" (Andressa). "[...] Eles tendo a base que a gente tem que é Deus no relacionamento, consequentemente eles vão ter [...]" (Ariane).

Apesar do número reduzido, consideramos que esses dados podem estar de acordo com o retorno da religiosidade no contemporâneo (CORTELLA; LA TAILLE, 2005) que, no entendimento de Llosa (2013), é de suma importância para a maioria das pessoas. Além do mais, Alves-Silva, ScorsoliniComin e Santos (2016) sublinharam que a religiosidade contribui para a permanência de um casamento duradouro. A fé de quem acredita que o matrimônio é sagrado, a valorização da união em várias religiões (ZORDAN; FALCKE; WAGNER, 2009) e o fato do casamento ser obra divina (COUTINHO; MENANDRO, 2010) foram aludidos como motivos para o enlace conjugal. Por sua vez, Comte-Sponville (2011) explicou que ágape é o amor divino. Também Deus foi relacionado ao conceito de amor nos trabalhos de Alves, Alencar e Ortega (2012, 2014), Alves et al. (2015a, 2015b) e de Estrella (2011).

As mulheres ainda sublinharam a 'questão pessoal', pois somente cabe à pessoa saber conduzir a relação e se o sujeito estiver com vontade de amar e de conviver com o outro, 'é possível' manter o amor no cotidiano. Também 'é possível' que o amor permaneça na vida a dois, em virtude do 'companheirismo'. Assim, explicou Poliana: “[...] É através disso, do companheirismo [...]” e Àgata: “[...] Pelo companheirismo [...]". Esses relatos nos remetem a Gilligan (1982), ao sublinhar a tendência da mulher em se definir e se avaliar em um contexto relacional em que exerce um papel de cuidadora e de companheira. Contudo, vale destacar que esse resultado parece distanciar-se do modelo de conduta que conferia às esposas o papel de responsável pela manutenção do casamento (DEL PRIORE, 2014), já que as participantes, ao se referirem sobre o companheirismo, não atribuíram essa função exclusivamente à mulher. Ademais, o companheirismo foi mencionado como expectativa em relação ao parceiro (FONSECA; DUARTE, 2014; STENGEL; TOZO, 2010) e ao casamento (ZORDAN; FALCKE; WAGNER, 2009).

Além disso, em conformidade com os nossos dados, na pesquisa de Jablonski (1991), os entrevistados proferiram que o companheirismo contribui para a manutenção do amor no convívio diário. No trabalho de Alves et al. (2015b) e no de Costa e Fernandes (2012), o companheirismo foi relacionado à definição de amor. Além do mais, vale ressaltar que o companheirismo é importante na edificação de uma vida em comum (MARIMÓN; VILARRASA, 2014) e é algo que se constrói no casamento (COSTA; MOSMANN, 2015).

Por fim, em 'outros', agrupamos as justificativas que não se inseriram nas demais categorias e foram proferidas apenas uma vez. Desses argumentos três foram pronunciados por mulheres entrevistadas no passado: um correspondeu à resposta 'é possível' e dois se referiram ao 'depende' ser ou não possível manter o amor na convivência. As participantes dos dias atuais mencionaram sete esclarecimentos - seis para justificarem a declaração 'é possível' e um para a resposta 'não é possível'. Dessa maneira, 'é possivel' manter o amor na conjugalidade em virtude do diálogo, do respeito, da amizade, do carinho, da crença na família, do bom-humor, porque não há motivos para não conservar o amor no cotidiano. Por outro lado, 'depende' de o amor permanecer ou não na união devido ao egoísmo, como também 'não é possível', já que a mídia não fala mais sobre a família. Vejamos alguns exemplos: "[...] Porque [...] Da mídia. Porque o que se fala? Não se fala mais sobre a família. [...]" (Aléxia). "[...] do diálogo, que é importantíssimo um diálogo 
sempre aberto, deve haver. [...]” (Poliana). "[...] É possível pelo respeito, não é? Pela amizade, pelo carinho, acho que dessa forma é possivel. $O$ amor [...]” (Àgata).

Sublinhamos que o fato de terem sido mencionados somente uma vez não diminui a relevância dos aspectos inseridos nessa categoria para a possibilidade ou não de os casais de modo geral manterem o amor na conjugalidade. Dessa maneira, destacamos a relação da amizade com o conceito de amor (ALVES, 2016; ALVES et al. 2015a, 2015b; ESTRELLA, 2011). Além disso, a amizade (MARIMÓN; VILARRASA, 2014; STENGEL; TOZO, 2010) é uma característica esperada em um parceiro amoroso, é construída no casal ao longo do casamento (COSTA; MOSMANN, 2015), predomina no amor companheiro (JABLONSKI, 1991), está presente no dia a dia conjugal (DEL PRIORE, 2014) e é estimada entre os cônjuges (MARIMÓN; VILARRASA, 2014).

Por sua vez, o respeito é fundamental para o desenvolvimento do juízo moral (PIAGET, 1994), é um ingrediente importante para a manutenção da relação amorosa (COSTA; MOSMANN, 2015; MATOS; FÉRES-CARNEIRO; JABLONSKI, 2005) e foi relacionado, com o carinho, ao conceito de amor nas pesquisas de Alves et al. (2015b) e de Estrella (2011).

Sobre o diálogo, ele foi enfatizado como um elemento relevante para as uniões amorosas nos estudos de Silva, Menezes e Lopes (2010) e de Smeha e Oliveira (2013). Também Alves-Silva, Scorsolini-Comin e Santos (2016) explicaram que o diálogo contribui para a permanência de um casamento duradouro. Lembramos ainda que o humor é uma virtude possível de ser desenvolvida pelos seres humanos (COMTE-SPONVILLE, 1999).

No que concerne à mídia, em Costa e Mosmann (2015), os participantes disseram que a mídia pode colaborar para o egoísmo e a intolerância e interferir na mudança do que se espera de um enlace amoroso.
Ademais, Costa (2004) discutiu que a 'moral do espetáculo' se utiliza da mídia na difusão dos ideais de felicidade e da vida como entretenimento, contribuindo para a desestabilização da família. Por outro lado, a crença no casamento (ALVESSILVA; SCORSOLINI-COMIN; SILVA, 2016) foi destacada na literatura. Finalizadas a apresentação e a discussão dos nossos resultados, teceremos as considerações finais deste estudo.

\section{Considerações Finais}

Neste estudo constatamos que a maioria das participantes considerou a possibilidade de os casais em geral manterem o amor no convívio diário e que 'sentimentos' foi a categoria que apresentou o maior número de justificativas apresentadas pelas mulheres. Contudo, não foi possível verificarmos a relação do amor com as virtudes morais (LA TAILLE, 2001) e com a construção do plano ético (LA TAILLE, 2010), uma vez que as entrevistadas enfatizaram os 'sentimentos' em si, e não uma articulação entre esses sentimentos e a edificação de uma conjugalidade boa e feliz para ambos os parceiros. Dessa maneira, sugerimos a realização de outros estudos com vistas a compreender a conexão do amor com as virtudes morais e com o plano ético na união conjugal.

Sublinhamos a maior porcentagem de explicações apresentadas por mulheres entrevistadas no passado em 'experiência' e consideramos que esse resultado pode estar relacionado com o fato de que essas participantes possuíam bases mais sólidas nas tradições do passado e nas perspectivas futuras (LA TAILLE, 2009), influenciando as suas vivências e a observação da experiência vivenciada por outros.

Averiguamos que a 'sorte', isto é, um aspecto próximo do acaso, foi proferida exclusivamente por mulheres entrevistadas no passado e, por outro lado, a 'religiosidade' foi aludida por mulheres que entrevistamos atualmente. Tal fato pode estar relacionado com retorno do religioso no 
contemporâneo (CORTELLA; LA TAILLE, 2005) e com a relevância da religião para a maior parte das pessoas (LLOSA, 2013). Dessa forma, esse resultado sugere que se investigue como as pessoas estão vivenciando a religiosidade nos dias atuais e de qual modo esse fator pode ou não influenciar as condutas dos sujeitos nas relações amorosas.

Por sua vez, a 'intolerância' foi mencionada apenas pelas entrevistadas nos dias de hoje. Essa categoria com a 'abdicação', os 'problemas conjugais' e a 'incompreensão' somaram 18\% das justificativas e são contrárias ao plano ético (LA TAILLE, 2010) e à ética do cuidado (GILLIGAN, 1982), pois, nessas categorias, a valorização do bem-estar, da felicidade e da singularidade de ambos os parceiros na relação amorosa não emergiu no relato das entrevistadas. Assim sendo, destacamos a relevância de elaborar projetos de intervenção que visem ao desenvolvimento das virtudes morais e de um juízo moral que contemple o eu e outrem na edificação de um projeto de vida ético.

Também destacamos a menção à 'reciprocidade', que é fundamental para o desenvolvimento da autonomia moral (PIAGET, 1994), e ao 'companheirismo', que se encontra presente na ética do cuidado (GILLIGAN, 1982). Contudo, da forma em que o companheirismo fora expresso pelas entrevistadas, pode indicar um distanciamento dos modos de conduta, vigentes até por volta dos anos de 1950, conforme os quais a mulher era a única responsável pela manutenção do casamento (DEL PRIORE, 2014). Ponderamos que o fato do respeito, da amizade, do carinho, do diálogo, da crença na família, da ausência de egoísmo e do bom humor ter sido mencionado apenas uma vez não reduz a importância desses aspectos na manutenção do amor no convívio diário.

Ajuizamos que este estudo se limitou a investigar a possibilidade ou não dos casais em geral manterem o amor no cotidiano e os fatores que podem ou não contribuir para essa permanência na concepção de jovens mulheres na classe média. Assim sendo, levantamos a importância de investigar o tema em questão com sujeitos que se encontram vivendo em conjugalidade por um período mais longo, por exemplo, 20 anos, de ambos os sexos, e em diferentes segmentos sociais, na perspectiva da moral e da ética.

Por último, sublinhamos que este estudo contribui para as pesquisas sobre o amor e os relacionamentos amorosos e fornece subsídios teóricos para psicólogos que desenvolvem trabalhos de intervenção com sujeitos de ambos os sexos e de todas as idades, em escolas, comunidades, grupos terapêuticos e/ou na clínica individual. Ademais, poderá auxiliar na elaboração de palestras, seminários e cursos que envolvam a temática da conjugalidade e/ou o amor e a sua relação com a moralidade.

\section{Referências}

ABOIM, S. Da pluralidade dos afetos: trajetórias e orientações amorosas nas conjugalidades contemporâneas. Revista Brasileira de Ciências Sociais, São Paulo, v. 24 n. 70, p. 107-122, jun. 2009.

ALENCAR, H. M. Depoimentos de amor: um estudo sob a ótica feminina. 1993. Dissertação (Mestrado em Psicologia) - Instituto de Psicologia da Universidade Federal do Rio de Janeiro, Rio de Janeiro, 1993.

ALVES, A. D. Amor e sua relação com a generosidade: estudo com adolescentes sob a ótica da moralidade. 2016. Tese (Doutorado em Psicologia) - Universidade Federal do Espírito Santo, Espírito Santo, 2016.

ALVES, A. D. et al. Concepção de amor e moralidade: estudo sob a ótica de jovens adultas. ARIÚS : Revista de Ciências Humanas e Artes, Campina Grande, v. 21, n. 1, jan./jun. 2015b.

ALVES, A. D. et al. Estudo exploratório acerca da concepção do amor e possibilidade de amar para adolescentes. C\&D-Revista Eletrônica da Fainor, Vitória da Conquista, v. 8 n.1, p. 158 - 173, jan./jun. 2015a.

Alves, A. D.; ALENCAR, H. M.; ORTEGA, A. C. Exemplos sobre a importância do amor: estudo com crianças no contexto da moralidade. Temas em Psicologia, Ribeirão Preto, v. 20, n. 1, p. 261 - 272, jun. 2012. 
AlveS, A. D.; AlEnCAR, H. M.; ORTEGA, A. C. Moralidade e concepção de amor em crianças de 6 e 9 anos. Revista Psicopedagogia, São Paulo, v. 31 n. 94, p. $21-34,2014$.

ALVES-SILVA, J. D.; SCORSOLINI-COMIN, F.; SANTOS, M. A. Conjugalidade e casamentos de longa duração na literatura científica. Contextos Clínicos, São Leopoldo, v. 9, n.1, p. 32-50, jun. 2016.

AMORIM, A. N.; STENGEL, M. Relações customizadas e o ideário de amor na contemporaneidade. Estudos de Psicologia, Natal, v. 19 n. 3, p. 157-238, jul./set. 2014.

BAUMAN, Z. Amor líquido: sobre a fragilidade dos laços humanos. Rio de Janeiro: J. Zahar, 2004.

CARVAlHO, F. C. G.; PAIVA, M. L. S. C. O olhar de três gerações de mulheres a respeito do casamento. Boletim de Psicologia, São Paulo, v. 59, n. 131, p. 223235, dez. 2009.

CHAVES, J. C. A percepção de jovens sobre os relacionamentos amorosos na atualidade. Psicologia em Revista, Belo Horizonte, v. 16, n. 1, p. 28-46, abr. 2010.

COMTE-SPONVILlE, A. $O$ amor. São Paulo: M. Fontes, 2011.

COMTE-SPONVILLE, A. Pequeno tratado das grandes virtudes. São Paulo: M. Fontes, 1999.

CONSELHO NACIONAL DE SAÚDE. Resolução $N^{o} 466 / 2012$. Diretrizes e normas regulamentadoras de pesquisas envolvendo seres humanos. Brasília, 2012. Disponível em: <http://www.conselho.saude.gov.br/ resolucoes/reso_12.htm>. Acesso em: 5 jan. 2017.

CORTELLA, M. S.; LA TAILLE, Y. Nos labirintos da moral. São Paulo: Papiros, 2005.

COSTA, C. B.; MOSMANN, C. P. Relacionamentos conjugais na atualidade: percepções de indivíduos em casamentos de longa duração. Revista da SPAGESP, Ribeirão Preto, v. 16, n. 2, 2015.

COSTA, J. F. O vestígio e a aura: corpo e consumismo na moral do espetáculo. Rio de Janeiro: Garamond, 2004.

COSTA, V.; FERNANDES, S. C. S. O que os adolescentes pensam sobre o amor e o sexo? Um estudo na perspectiva das representações sociais. Psicologia \& Sociedade, Belo Horizonte, v. 24 n. 2, p. 391 - 401, maio/ago. 2012.

COUTINHO, S. M. S.; MENANDRO, P. R. M. Relações conjugais e familiares na perspectiva de mulheres de duas gerações: "Que seja terno enquanto dure". Psicologia Clínica, Rio de Janeiro, v. 22, n. 2, p. 83-106, 2010.

DEL PRIORE, M. Histórias e conversas de mulher: amor, sexo, casamento e trabalho em mais de 200 anos de história. São Paulo: Planeta, 2014.
DELVAL, J. Introdução à prática do método clínico: descobrindo o pensamento das crianças. Porto Alegre: Artmed, 2002.

ESTRELlA, N. R. Significado del Amor en la Adolescencia Puertorriqueña. Acta de Investigación Psicológica, México, v. 1, n. 3, dez. 2011.

FERRY, L. Do amor: uma filosofia para o século XXI. Rio de Janeiro: Difel, 2013.

FONSECA, S. R. A.; DUARTE, C. M. N. Do namoro ao casamento: significados, expectativas, conflito e amor. Psicologia: Teoria e Pesquisa, Brasília, v. 30, n. 2, p. 135 - 143, abr./jun. 2014.

GIDDENS, A. A transformação da intimidade: sexualidade, amor e erotismo nas sociedades modernas. São Paulo: EDUNESP, 1993.

GILLIGAN, C. Uma voz diferente: psicologia da diferença entre homens e mulheres da infância à idade adulta. Rio de Janeiro: Rosa dos Tempos, 1982.

JABLONSKI, B. Até que vida nos separe: a crise do casamento contemporâneo. Rio de Janeiro: Agir, 1991.

LA TAILLE, Y. Desenvolvimento moral: a polidez segundo as crianças. Cadernos de Pesquisa, São Paulo, n. 114, p. 89 - 119, nov. 2001.

LA TAILLE, Y. Formação ética: do tédio ao respeito de si. Porto Alegre: Artmed, 2009.

LA TAILLE, Y. Moral e ética: uma leitura psicológica. Psicologia: Teoria e Pesquisa, Brasília, v. 26, n. esp., p. 105-114, 2010.

LlOSA, M. V. A civilização do espetáculo: uma radiografia do nosso tempo e da nossa cultura. Rio de Janeiro: Objetiva, 2013.

MARIMÓN, M. M.; VILARRASA, G. S. Como construímos universos: amor, cooperação e conflito. São Paulo: UNESP, 2014.

MATOS, M.; FÉRES-CARNEIRO, T.; JABLONSKI, B. Adolescência e relações amorosas: um estudo sobre jovens das camadas populares carioca. Interação em Psicologia, Curitiba, v. 9 n. 1, p. 21-33, jan./jun. 2005.

OLIVEIRA, D. S. Conjugalidade e a união de duas histórias de vida: uma discussão ilustrada a partir do filme a história de nós dois. Interação em Psicologia, Curitiba, v. 16 n.1, p. 125-133, jan./jun. 2012.

OLTRAMARI, L. C. (2009). Amor e conjugalidade na contemporaneidade: uma revisão de literatura. Psicologia em Estudo, Maringá, v. 14 n. 4, p. 669-677, out./dez. 2009. 
PIAGET, J. O juízo moral na criança. São Paulo: Summus, 1994. (Obra original publicada em 1932).

ROLIM, K. I.; WENDLING, M. I. A história de nós dois: reflexões acerca da formação e dissolução da conjugalidade. Psicologia Clínica, Rio de Janeiro, v. 25 n. 2 , p. $165-180,2013$.

SENNA, M. F. N. Politicas públicas de distribuição de renda sua influência na mobilidade social: o caso da nova classe média brasileira. 2015. Dissertação (Mestrado em Ciência Política) - Centro Universitário Unieuro, Brasília, DF, 2015.

SILVA, I. M.; MENEZES, C. C.; LOPES, R. C. S. Em busca da "cara-metade": Motivações para a escolha do conjugue. Estudos de Psicologia (Campinas), Campinas, v. 27 n. 3, p. 383-391, jul./set. 2010.

SMEHA, L. N.; OLIVEIRA, M. V. Os relacionamentos amorosos na contemporaneidade sob a óptica dos adultos jovens. Revista Psicologia: Teoria e Prática, São Paulo, v. 15 n. 2 , p. 33 - 45, ago. 2013.
STENGEL, M.; TOZO, S. M. P. S. Projetos afetivosexuais por adolescentes e seus pais. Pesquisas e Práticas Psicossociais, São João Del-Rei, v. 5 n. 1, p. 72-82, jan./ jul. 2010.

VIEIRA, E. D.; STENGEL, M. Os nós do individualismo e da conjugalidade na pós-modernidade. Aletheia, Canoas, n. 32, p.147 - 160, ago. 2010.

ZORDAN, E. P.; FALCKE, D.; WAGNER, A. Casar ou não casar? Motivos e expectativas com relação ao casamento. Psicologia em Revista, Belo Horizonte, v. 15 n. 2, p. 56-76, ago. 2009.

\section{Agradecimentos}

Agradecemosà Coordenação deAperfeiçoamento de Pessoal de Nível Superior (Capes) e à Fundação de Amparo à Pesquisa e Inovação do Espírito Santo (Fapes) pelo apoio financeiro. 